\title{
The Sustainable Development Goal on Water and Sanitation: Learning from the Millennium Development Goals
}

\author{
Johanna Weststrate ${ }^{1} \cdot$ Geske Dijkstra $^{1}$ - Jasper Eshuis ${ }^{1} \cdot$ Alberto Gianoli $^{2}$. \\ Maria Rusca ${ }^{3}$
}

Accepted: 8 July 2018 / Published online: 25 August 2018

(c) The Author(s) 2018

\begin{abstract}
Target 7c of the Millennium Development Goals (MDG 7c) aimed to halve the population that had no sustainable access to water and basic sanitation before 2015. According to the data collected by the Joint Monitoring Programme in charge of measuring progress towards MDG 7c, 2.6 billion people gained access to safe water and 2.3 billion people to basic sanitation. Despite these optimistic figures, many academics have criticised MDG 7 c. We provide an overview of this critique by performing a systematic literature review of 62 studies conducted over the MDG implementation period (2002-2015) and shortly after. Our objective is to contribute to the debate on the operationalisation of the Sustainable Development Goal on water and sanitation (SDG 6). The academic debate on MDG $7 \mathrm{c}$ mainly focused on the effectiveness of the indicators for safe water and sanitation and on the political dynamics underlying the selection of these indicators. SDG 6 addresses some of the concerns raised on the indicators for safe water and sanitation but fails to acknowledge the politics of indicator setting. We are proposing additional indicators and reflect on the limitations of using only quantitative indicators to measure progress towards SDG 6.
\end{abstract}

Keywords Millennium development goals · Sustainable development goals · Water · Sanitation

Electronic supplementary material The online version of this article (https://doi.org/10.1007/s1120 5-018-1965-5) contains supplementary material, which is available to authorized users.

Johanna Weststrate

weststrate@fsw.eur.nl

1 Department of Public Administration, Erasmus University Rotterdam, Mandeville Building Room T17 -12, P.O box 1738, Rotterdam, The Netherlands

2 Institute for Housing and Urban Development Studies, Erasmus University Rotterdam, Rotterdam, The Netherlands

3 Department of Geography, King's College London, London, UK 
Table 1 JMP indicators for sustainable access to safe water and basic sanitation (WHO/UNICEF 2016)

\begin{tabular}{lc}
\hline 'Improved' sources of drinking water & 'Unimproved' sources of drinking water \\
Piped water into dwelling, piped water to yard/plot, public tap or & $\begin{array}{c}\text { Unprotected spring, unprotected dug } \\
\text { well, cart with small drum/well, }\end{array}$ \\
standpipe, tube well or borehole, protected dug well, protected & $\begin{array}{l}\text { tanker-truck, surface water, bottled } \\
\text { spring, rain water }\end{array}$ \\
& water \\
'Improved' sanitation & 'Unimproved' sanitation \\
$\begin{array}{l}\text { Flush toilet, piped sewer system, septic tank, flush/pour flush to } \\
\text { pit latrine, ventilated improved pit latrine (VIP), pit latrine with } \\
\text { slab, composting toilet, special case }\end{array}$ & $\begin{array}{c}\text { Flush/pour flush to elsewhere, pit } \\
\text { latrine without slab, bucket, hanging } \\
\end{array}$ \\
& $\begin{array}{l}\text { toilet or hanging latrine, shared sani- } \\
\text { tation, no facilities, or bush or field }\end{array}$ \\
\hline
\end{tabular}

\section{Introduction}

The Millennium Development Goals (MDG) campaign was launched in 2002 and ran until 2015. Its overall objective was to halt extreme poverty (United Nations 2017). The campaign, adopted by 189 UN member states, set eight development goals (WHO 2017a). Target $7 \mathrm{c}$ aimed to halve the number of people without sustainable access to safe water and basic sanitation, including hygiene. The target was repeatedly edited until it was adopted in 2006. Drinking water and sanitation access is key to disease prevention. Diarrhoeal disease alone is responsible for the deaths of 1.5 million people every year, including 360,000 children under the age of five, mostly in low-income countries. It is estimated that $58 \%$ of diarrhoeal diseases can be attributed to unsafe water supply, sanitation and hygiene (WHO 2017b).

The MDGs were succeeded by the Sustainable Development Goals (SDGs) for the 2016-2030 period, including a self-standing goal-SDG 6-regarding access to water and sanitation. MDG 7c and SDG 6 guide water and sanitation data that are collected worldwide and that determine what we know about access to water and sanitation. The goals influence national policies, donor funding strategies (Cotton and Bartram 2008; Bain et al. 2012) and service delivery to a large part of the world population.

Progress towards MDG 7c was measured by the World Health Organisation (WHO) and the United Nations Children's Fund (UNICEF) through the Joint Monitoring Programme for Water Supply and Sanitation (JMP). JMP measures access to 'improved and unimproved' water sources and 'improved and unimproved' sanitation facilities as indicators for safe water and basic sanitation access (Table 1). Estimates are based on survey data, including Demographic and Health Surveys (DHS), UNICEF Multiple-Indicator Cluster Surveys (MICS), World Bank Living Standards Measurement Surveys (LSMS), WHO World Health Surveys (WHS) and national censuses and surveys (Bartram et al. 2014; Cotton and Bartram 2008).

Progress made over the course of the MDGs is impressive. According to JMP statistics, the targets set for access to safe drinking water were met in 2010, 5 years before the deadline (United Nations MDG Monitor 2017). Between 1990 and 2015, 2.6 billion people gained access to 'improved' drinking water sources, and 2.1 billion people gained access to 'improved' sanitation. The number of people practising open defecation has gone down by nearly $50 \%$ since 1990 .

The outcomes of our systematic literature review on MDG 7c, however, indicate that these figures may be too optimistic and raises the question whether progress towards MDG 
$7 \mathrm{c}$ has been sustainable and equitable. The objective of this study is to provide an overview of criticism of MDG target $7 \mathrm{c}$ and contribute to the ongoing debate on the SDGs. In the following sections, we present the method used to identify and select relevant papers, the main outcomes of the systematic literature review and its implications for the development of indicators in the context of SDG 6.

\section{Method}

This study uses a PRISMA systematic literature review (Moher et al. 2009), which is based on a systematic, step-by-step process for selecting the literature and aims to limit bias and increase scientific reliability. We chose to focus on the academic debate on MDG 7c. Grey literature is often written by organisations in charge of developing the MDG targets and indicators, whereas we aimed to offer an external perspective.

\subsection{Search Strategy}

We conducted an automated search in two major academic databases: ISI Web of Science and Scopus, on 3 June 2016. Our search was limited to the social sciences domain, our field of expertise. Web of Science and Scopus provide very good coverage of journals in the Social Sciences. The search included studies published during the MDG campaign (2002-2015) and shortly after, to be able to take into account criticism of the MDGs during its running time and shortly after, when authors had the opportunity to look back and reflect on the implementation of MDG 7c. The results were exported and filtered in a Microsoft Excel table. The search string combined the keywords: water OR sanitation AND “Millennium Development Goals” OR "Sustainable Development Goals" OR “Joint Monitoring Programme”.

\subsection{Selection Criteria and Qualitative Analysis}

The search resulted in 113 publications: 27 in ISI Web of Science and 86 in Scopus. Criteria for inclusion and exclusion were applied to refine our selection of studies to be reviewed (Fig. 1). To ensure scientific quality, we included peer reviewed academic articles only. We included articles in English with a focus on MDG 7c and the Joint Monitoring Programme. In addition, we included articles focusing on SDG 6 but starting with the shortcomings of MDG 7c, often providing criticism of MDG 7c and recommendations on how to resolve weaknesses in light of SDG 6. We included papers based on quantitative and qualitative data to avoid a predisposition towards a positivist or interpretive research approach.

We excluded articles that focused primarily on other MDG targets or on entirely different subject areas, such as armed conflict, green building strategies or rural livelihoods. We eliminated nine duplicates, which were articles extracted from both databases. Applying the criteria for inclusion and exclusion, we removed 37 records. After reading the remaining articles in their entirety, we excluded five more records. Two of these did not comply with the selection criteria because, though the abstract was in English, they were written in another language (Spanish, German). The remaining three articles did not focus on MDG $7 c$.

We applied a conventional qualitative content analysis (Hsieh and Shannon 2005) with Atlas $\mathrm{Ti}$ to analyse texts with coding categories derived inductively from the text. We 


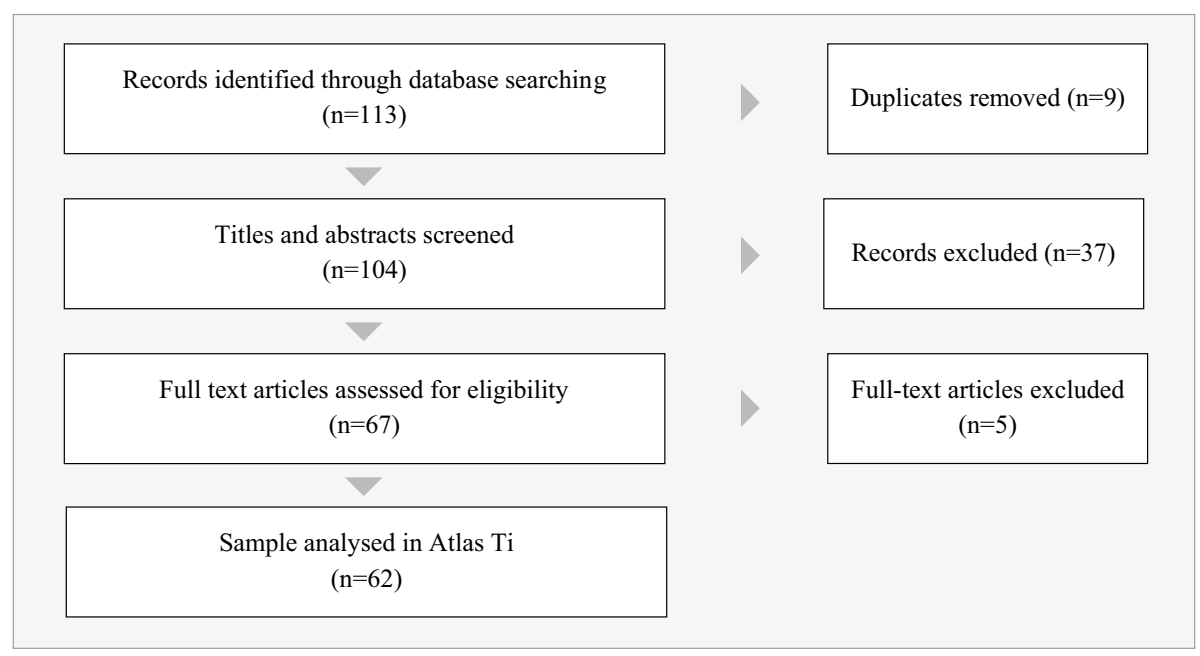

Fig. 1 PRISMA flow diagram

were able to distinguish four thematic categories in the literature with regard to MDG 7c (Table 2). Papers belonging to the same category were grouped together in a so-called document family. Some papers fitted into multiple categories. Each category/family was systematically analysed by scrutinising all articles on themes, research designs and outcomes. We looked for recurring qualitative and quantitative evidence for the critique presented.

The main investigator/author extracted the studies, and the selection process was double-checked by two co-authors. The articles in the sample were published in interdisciplinary journals in the areas of development, health, environment, urban studies, political science and engineering. The review protocol and research supplement are available online: http://hdl.handle.net/1765/106288. A limitation of the study was that it was limited to social science research. As scientific disciplines, such as the natural and medical sciences were excluded, criticisms related to those aspects may have been overlooked.

\section{Research Outcomes}

The first publications on the MDGs date back to 2006. The number of articles peaked between 2012 and 2014, coinciding with the policy debate on SDG targets. We identified four streams of literature in the academic debate on MDG 7c:

1. The indicators 'improved/unimproved water source' and 'improved/unimproved sanitation facility' (21 articles). In this category, authors criticise the MDG indicators for safe water and basic sanitation and suggest alternatives. In many cases, arguments are supported with quantitative data such as international surveys or primary survey data.

2. Integrated water resources management ( 5 articles). The central theme here is the water cycle from water extraction to wastewater disposal or water reuse, with studies examining water saving technologies, for instance, and proposing indicators for wastewater treatment. 


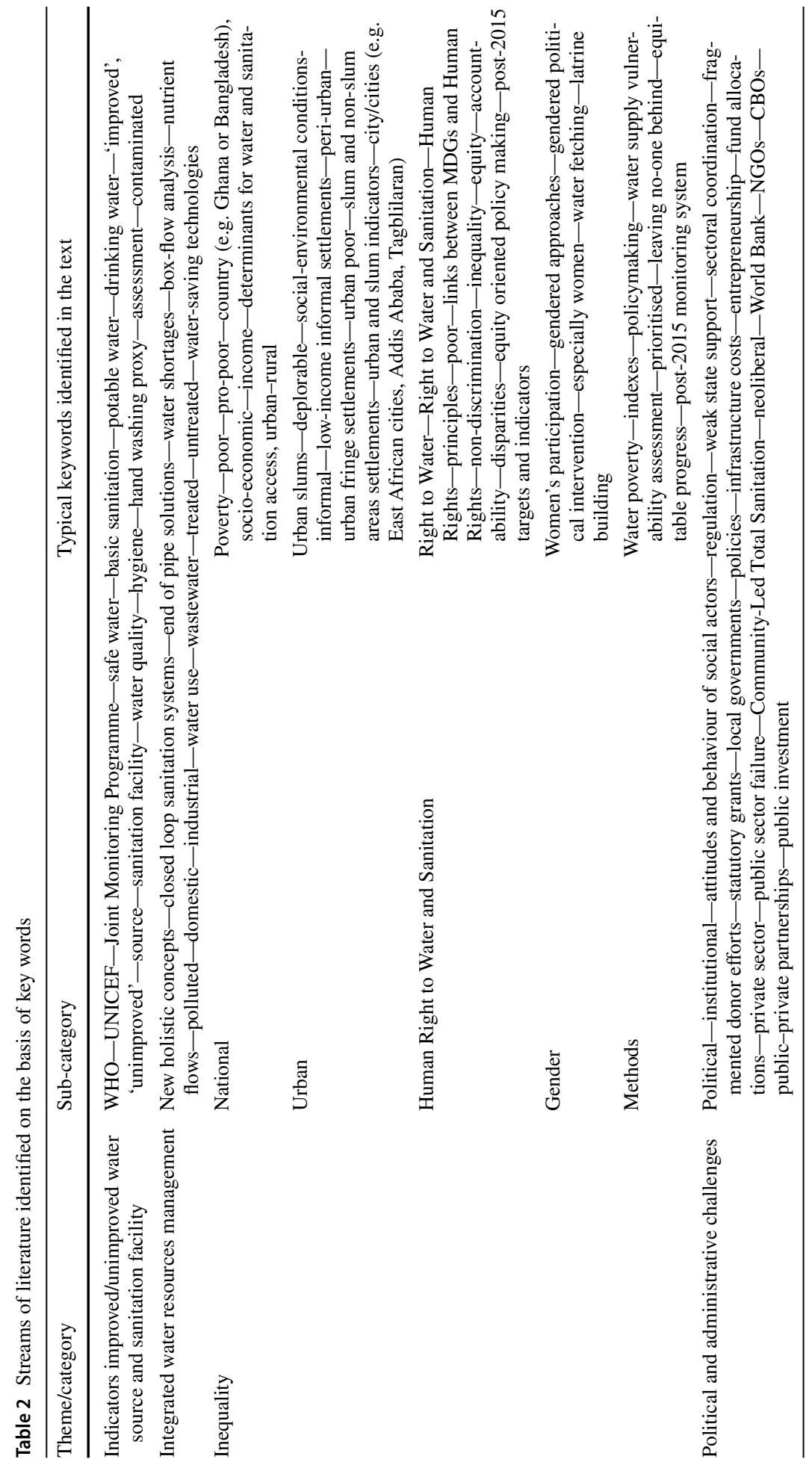


3. Inequality ( 32 articles). This category consists of a wide range of studies, ranging from case studies at national or local levels to statistical analyses. Authors often focus on the question whether or not vulnerable groups have been reached, a concern that is not surprising as the MDGs set out to eradicate extreme poverty. Studies also criticise the way access to safe water and basic sanitation has been measured and propose ways to monitor equity in access. This inequality category was subdivided into five sub-categories: national inequality, urban inequality, gender, Human Right to Water and Sanitation and methods to measure inequality. The Human Right to Water and Sanitation is based on the principles of non-discrimination and equality.

4. Political and administrative challenges ( 21 articles). Studies in this category offer a detailed insight into political dynamics at national and local levels, mainly through case studies. Several articles focus on the advantages and disadvantages of privatisation and community-based management versus provision by government organisations. Studies reveal that governments and other actors do not always take their responsibility when it comes to providing water and sanitation services in low- and middle-income areas.

We established these categories in Atlas Ti on the basis of keywords (Table 2). The article supplement provides a full overview of the articles in each category. A large number of articles fall into two categories, such as those that describe how government policies affect low-income groups, which fall into the categories of inequality and political and administrative challenges.

The main critique throughout these categories is aimed at shortcomings in the indicators for safe water and basic sanitation and the politics of setting and mobilising indicators. The category of 'indicators improved/unimproved water source and sanitation facility' points out the weaknesses in the MDG indicators used to measure access to safe water and basic sanitation. The literature in the category of 'integrated water resources management' shows that the MDG indicator fails to take water scarcity into account. Access to safe water and basic sanitation by different (income and ethnic) groups, with concerns relating to distributive justice, has not been measured consistently, according to studies that come into the 'inequality' category. Criticisms related to the politics of setting and mobilising indicators can be found in all categories but are most explicitly addressed in the category of 'political and administrative challenges'.

\subsection{Shortcomings in the Indicators for Safe Water and Basic Sanitation}

A main finding of the review is that the indicator of 'access to an improved water source' fails to take water quality into account. As a result, water sources defined as improved may contain contaminated water and vice versa. A water quality assessment in rural Cambodia, for example, showed that the water quality of rope pump wells, considered an 'improved' water source, often failed to meet health standards (Bennett et al. 2010). Of the samples coming from 'unimproved' open wells, $18.3 \%$ were unsafe according to the Cambodian drinking water standards, compared to $31.7 \%$ of samples from the 'improved' rope pump wells. The indicator of 'improved source' covers a wide variety of water supply options, some better than others (Bartram et al. 2014; Brown et al. 2013). A survey including 224 households in the Dan Nang province in Vietnam indicated that the quality of piped water was higher than the quality of other improved sources (Brown et al. 2013). The prevalence of diarrhoea was lower among households with access to piped water. When water quality is included as an indicator, the population with sustainable access to safe water 
decreases drastically. From October 2004 to April 2005, JMP conducted a Rapid Assessment of Drinking-Water Quality (RADWQ) in eight countries (Bain et al. 2012), aiming to assess whether an indicator for water quality was the way forward for the JMP. Two articles compared RADWQ estimates with JMP estimates based on the indicator 'access to an improved/unimproved water source' (Bain et al. 2012; Onda et al. 2012). Extrapolation of the RADWQ data reveals that the estimated population with access to safe drinking water in 2008 and 2010 declined when water quality was used as an indicator: the population with access to safe water decreased by $11 \%$ in Ethiopia, by $16 \%$ in Nicaragua, by $15 \%$ in Nigeria and by 7\% in Tajikistan (Bain et al. 2012). Onda et al. (2012) estimated that 1.8 billion people worldwide used unsafe water in 2010. The JMP estimate for that same year was 783 million people, significantly lower. Authors, therefore, recommend including water quality as a parameter to measure access to safe drinking water in the context of the SDGs. Other relevant parameters to be incorporated include water fetching (Sorenson et al. 2011) and functionality (Bartram et al. 2014). Indicators for safe drinking water defined in the context of the 2002 Declaration of Human Right to Water were frequently mentioned throughout the sample: water availability, quality, acceptability, physical accessibility and affordability. ${ }^{1}$ By adding these indicators, water quality in particular, estimations of people with access to safe drinking water will be more precise.

The indicator of 'access to an improved sanitation facility' does not take into account safe collection, treatment and disposal of wastewater and faecal sludge, vital to disease prevention. ${ }^{2}$ In dense urban areas, pit latrines and septic tanks have to be properly emptied by trucks or other vehicles with a tank and vacuum pumps and the contents should be transported to a treatment plant and treated before disposal into the environment. When faecal sludge is unsafely dumped inside urban areas or infiltrates through pit latrines, it causes environmental pollution and diseases. Contaminated ground water sources are unsuitable for drinking purposes. Human contact with faecal waste leads to infections caused by viruses (e.g. rotavirus, norovirus), bacteria (e.g. vibrio cholera, Shigella soo, Campulibacter spp.) and protozoae (e.g. entamoebe histolyca, cryptosporidium) and may cause other diseases related to faecal contamination (Baum et al. 2013). When the indicator for basic sanitation is modified to include the treatment of wastewater and faecal sludge, the estimate of people with access to sanitation is much lower (Baum et al. 2013; Santos 2013; Satterthwaite 2016). JMP's estimate of the world population using basic sanitation was $62 \%$ in 2010. When treatment is included as a criterion for access to basic sanitation, the estimate goes down to $40 \%$ of the population (Baum et al. 2013). A study in Bhutan on poverty reduction compared the JMP estimates with estimates based on an indicator that required basic sanitation options to be connected to a septic tank or sewage network (Santos 2013). On the basis of the JMP indicators, $20 \%$ of the population in Bhutan did not have access to sanitation in 2003 compared to $18 \%$ in 2007 . On the basis of the more ambitious indicator of septic tanks, the population deprived of sanitation was estimated at $78 \%$ in 2003 and

\footnotetext{
1 The General Comment No. 15, adopted by the UN committee in 2002, provides guidelines for states on interpreting the Right to Water. The indicators for safe drinking water access captured in General Comment 15 are frequently mentioned with or without reference to the Right to Water: water availability, quality, acceptability, physical accessibility and affordability (e.g., Bartram et al. 2014; Anand 2007; Flores Baquero et al. 2016; Koff and Maganda 2016; Zawahri et al. 2011).

${ }^{2}$ Collection, treatment and disposal of faecal sludge and wastewater, aiming to protect the population from exposure to human excreta, is to be taken into account when measuring progress towards MDG 7c and SDG 6 (Baum et al. 2013; Cotton and Bartram 2008; Gunawardana and Galagedara 2013; Malik et al. 2015; Satterthwaite 2016).
} 
$62 \%$ in 2007. Several authors also suggest including an indicator on facilities maintenance (i.e. 'is the facility clean and functional') and hand washing. Hand washing is not common practice in low- and middle-income countries but is key to avoiding disease transmission, especially among young children (Shelus and Hernandez 2015). Instead of reporting on the binary indicators of 'improved/unimproved' water sources and sanitation facilities, authors recommend using a hierarchical scale that distinguishes different levels of access to water and sanitation (Bartram et al. 2014; Gunawardana and Galagedara 2013). Though an unlined pit latrine does not have the same environmental and health benefits as a toilet connected to sewers and a functioning wastewater treatment plant, both options are classed together in the same category. Gunawardana and Galagedara (2013) propose a new monitoring method to overcome these deficiencies. Their method is composed of two subindices: 'latrine security and hygiene' and 'treatment and disposal'. The authors differentiate 12 hierarchical levels of sanitation, ranging from 'very poor sanitation and unhygienic latrine with unimproved treatment and disposal' to 'hygienic latrine with improved treatment and disposal'.

MDG 7c did not include targets and indicators on wastewater treatment and integrated water resources management. Wastewater remains untreated in many countries in East and Southeast Asia, North Africa and Eastern and Southern Europe (Flörke et al. 2013) and is often dumped in freshwater bodies untreated. It is a global priority to reduce the amount of untreated wastewater. Water saving through water reuse, low flush toilets and dry toilets should be introduced into water-scarce countries (Erni et al. 2010; Flörke et al. 2013; Rouse 2014). Two studies investigate so-called dry closed-loop latrines: the Terra Preta sanitation system (De Gisi et al. 2014) and the green latrine (Laré-Dondarini 2015). Terra Preta is black earth from the Amazon Basin with the capacity to convert bio-waste and faecal matter into fertile soil. Neither the Terra Preta sanitation system nor the green latrine uses water. Urine and faecal matter are separated inside dry latrines and used for agriculture. Dry latrines are cheap because they do not require a piped network or transport and wastewater treatment plants. It remains questionable, however, whether dry latrines are an adequate sanitation option in dense urban environments. The uptake of the green latrine was investigated in Dapaong, Togo, a city of 68,650 inhabitants. One of the outcomes of this study was that farmers were more likely to choose green latrines because of the agricultural benefits. Educated households did not like to handle dried faecal matter and chose other sanitation options. The literature points to the importance of promoting integrated water resources management to address water scarcity and the lack of wastewater treatment.

While it is the ambition of the MDGs to eliminate extreme poverty, the studies reviewed found that lack of consistent disaggregated data complicates efforts to assess the impact of MDG 7c on disadvantaged groups. Academics and professionals in the water and sanitation sector have advocated new methods to measure inequality during the MDG running period, ${ }^{3}$ which should be used for policy development. Inspired by the recognition of the Human Right to Water and Sanitation in 2010, the JMP Equity and Non-Discrimination Working Group developed a strategy to collect disaggregated data (Satterthwaite 2014). The group recommended making a distinction between rich/poor groups, urban/rural, slums/formal urban settlements and disadvantaged groups/general population. Disparities between groups can be measured by comparing the access of disadvantaged groups

\footnotetext{
3 Several authors in the sample suggest measuring inequality (Bartram et al. 2014; Cho et al. 2010; Hadipuro 2007; Kite et al. 2014; Flores Baquero et al. 2016; Satterthwaite 2014).
} 
to water and sanitation with that of advantaged groups or the national average (Flores Baquero et al. 2016; Satterthwaite 2014; Kite et al. 2014). In the sample, we found examples of geographical, ${ }^{4}$ gender ${ }^{5}$ and ethnic inequalities ${ }^{6}$ with regard to access to safe water and basic sanitation. Many articles focus on progress towards MDG 7c in urban lowincome areas, referred to as informal settlements or slums. Some of these settlements have been around for decades; others were established more recently in the urban fringes and continue to grow. Access to safe water and basic sanitation is still relatively low in these areas. The literature highlights that quality in access to water and sanitation was not adequately addressed during the MDGs.

\subsection{The Politics of Setting and Mobilising Targets and Indicators}

Case studies examine whether governments and other actors live up to their commitment to MDG 7c. In low-income areas, where formal utilities are unwilling or unable to provide services though centralised water supply and sewerage networks, people often depend on small-scale providers offering a wide range of services. Water providers dig boreholes and develop small-scale networks or sell water bottles. Contractors build pit latrines and install septic tanks. When pit latrines and septic tanks fill up, a provider operating a vacuum truck or vacutug (a small emptying vehicle) is hired to transport faecal waste to a treatment centre. In the previous section, we have discussed the health and environmental risks related to inadequate collection, treatment and disposal of faecal sludge. Several authors point out that it is the government's role to reduce these risks by providing regulations for providers and users and by expanding government-owned piped water supply and sewerage infrastructure (Anand 2007; Aguilar and de Fuentes 2007; Ayalew et al. 2014; Fisher 2008; Rouse 2014; Schaub-Jones 2010).

The MDG indicators may have provided an incentive for governments not to invest in piped water supply and sewage networks (Satterthwaite 2016; Zawahri et al. 2011). Boreholes, protected wells, pit latrines and septic tanks, financed with private resources and often unregulated, are a cheap way of providing water and sanitation in low- and middleincome areas. These options are included by JMP as 'access to safe water and basic sanitation', but they do not encourage governments to finance expansion of the water supply and sewage network.

\footnotetext{
${ }^{4}$ In Ghana, housing including sanitation is neglected in rural areas (Adjei and Kyei 2013). Consequently, there is a high incidence of malaria, skin diseases and diarrhoeal diseases among children in low-income households. In addition to urban/rural inequalities, there are regional inequalities in Ghana (Adams et al. 2016). In Malawi (Gutierrez 2007), water points are distributed unevenly in the rural areas. Water mapping exercises, carried out with a handheld GPS, reveal the exact locations of water sources. These exercises are a useful tool to make sure that investments are distributed equally across the rural areas.

5 Women are a disadvantaged group with regard to access to drinking water and sanitation. In some countries, cultural norms dictate that women are responsible for water fetching and/or cannot be seen using a latrine. An analysis of the MICS-3 survey in 44 countries indicates that, in $58.7 \%$ of cases, women are responsible for water fetching, followed by men $(30.7 \%)$ and children $(9.1 \%)$, at the expense of incomegenerating activities (Sorenson et al. 2011). In rural areas in Rajasthan, India, women are not supposed to relieve themselves out in the field during the day. They have to wait till dark, to avoid being seen by others. A German-funded project aimed to improve the women's situation by building latrines but failed. The latrines were used mainly by men and guests because they were located close to the road and because these latrines were perceived as a status symbol (O'Reilly 2010).

${ }^{6}$ Refugee and nomadic groups are an underserved group in the Middle East, in particular Palestinian refugees (Zawahri et al. 2011).
} 
Case studies show that national and local governments, despite their commitment to the Millennium Development Goals, do not always take charge. In India, regardless of its economic progress, the government did not expand centralised drinking water networks between 1997 and 2007 (Anand 2007). This particularly affects low-income groups. Two studies point out that the Indian central government fails to consistently provide grants to local authorities for basic services (Rajaraman and Gupta 2016; Snehalatha and Anitha 2012). In Malawi and Zambia there is limited government support for increasing water and sanitation access (Gutierrez 2007). In Zambia, the government does not allocate sufficient funding to projects in the water and sanitation sector, and, as a result, less than a fourth of the projects authorised by the government is actually implemented. Malawi has a funding mechanism called Pro-Poor Expenditures (PPEs). The share of water and sanitation expenditures went down from 5\% in 2001-2001 to $1 \%$ in 2003-2004. Donors contribute to the problem by financing projects that are not in line with existing pro-poor policies. In Cancún, Mexico, informal settlements near the city centre and in the peri-urban areas are not connected to the sewerage system (Aguilar and de Fuentes 2007). Untreated sewage and faecal sludge contaminates the groundwater - the city's source of drinking water-and the sea and lagoons along the coastline. The local government and the private operator have delayed the development of a sewerage network. The authors suggest relocating residents from the groundwater extraction areas, installing sanitation infrastructure and imposing stronger regulations on water and sanitation providers and users. A similar case is the city of Tagbilaran, where groundwater sources are used for drinking. Local politicians ignore the risk of drinking water contamination (Fisher 2008). Over-extraction of groundwater in Tagbilaran leads to salt water intrusion, with inadequate collection and disposal of waste, sewage and faecal sludge exacerbating contamination.

Small-scale water providers operating in low- and middle-income areas in Kisumu (Kenya) and Addis Ababa (Ethiopia) remain unregulated by the government (Ayalew et al. 2014), while the water provided is not suitable for drinking in many cases: $84 \%$ of the 318 water samples taken from small-scale water providers in in Kisumu and $40 \%$ of the 96 samples taken from small-scale providers in Addis Ababa tested positive for thermotolerant coliforms, an indicator of faecal contamination. In Kisumu, the Water Act (2002) stipulates that water providers can only supply water below a certain quantity; a license is required for quantities over these limits, but only the Water Services Boards are eligible to apply for such licenses. As a result, small-scale water providers often operate illegally and their service provision is neither monitored nor regulated. In Addis Ababa, like in Kisumu, small-scale water providers operate outside the legal system.

As indicators of water and sanitation coverage are an indication of political performance, governments may attempt to 'adjust' the definitions of indicators in their favour to demonstrate their success in the delivery of water and sanitation services. The distance to a water source, for instance, is crucial for calculating safe water access figures. Access figures will change drastically, however, if the national statistics bureau sets the maximum distance from an improved water source from 500 metres to 1500: at 500 metres, significantly fewer people have access.

In Ethiopia, pressure to perform at the national level led to the overestimation of access to safe drinking water in the Southern Region in 2007 (Welle 2014). Three methods were used for calculating access. The first method calculated all users within 1500 metres of a functional water source. The second method added users from beyond the 1500 metres threshold. The third method added up average users per functional source, which led to the highest access figures. During a visit to the Region, the Minister insisted on using the third 
method. As a result of such inflated access figures, the budget allocated to this region was insufficient to cover its real needs.

There are several other examples of this strategy. India's progress in the water sector is based on the definition of distance to source of 1600 metres, undervaluing physical labour (Anand 2007). Only a small proportion of households in India fetch water farther than that. In the Middle East and North Africa Region, official designations of rural and urban areas are outdated, allowing governments to deliver services to formally designated urban areas and exclude rapidly growing villages, hamlets and secondary cities (Zawahri et al. 2011: UNDP and INP 2004). The literature shows how governments may selectively use and strategically adapt MDG 7c indicators in ways that fit their political interests.

\subsubsection{Sustainable Development Goal 6: Towards More Comprehensive Indicators}

Sustainable Development Goal 6 aims to achieve universal coverage by calling for availability and sustainable management of water and sanitation for all before 2030 (Table 3). The SDG 6 targets and indicators address the shortcomings in the indicators as identified by academics in this systematic literature review but fail to acknowledge the political dimension behind the indicators. ${ }^{7}$

Target 6.1 'To achieve universal and equitable access to safe and affordable drinking water for all' is measured by the indicator 'proportion of population using safely managed drinking water services'. Safely managed drinking water services, in their turn, are defined as 'drinking water from an improved source which is located on the premises, available when needed and free from contamination and priority contamination' (WHO 2017c). The shortcomings in the indicators identified by our systematic literature review have been addressed by the SDG 6.1 indicator. Added dimensions include the location of the source (accessibility), affordability, continuity of water supply and water quality.

It is still under discussion how these new parameters are to be measured. Affordability will probably be measured by the amount spent on water in relation to a household's total expenditure. It is complicated to measure this indicator as a household's income often changes significantly over time. The accessibility indicator will be measured through selfreported journey times. To measure if water is safe for drinking, JMP intends to measure the presence of $E$. coli bacteria, an indicator of faecal contamination. Water samples will be tested during household surveys. JMP has been experimenting with water quality testing in collaboration with UNICEF's MICS programme. Drinking water has also been tested for arsenic and fluoride. Testing for E.coli is a good start, but it is important to add other parameters, such as salinity, in some contexts.

Target 6.2 'To achieve access to adequate and equitable sanitation and hygiene for all and end open defecation, paying special attention to the needs of women and girls and those in vulnerable situations' will be measured by the indicator 'Proportion of population using safely managed sanitation services, including a hand-washing facility with soap and water'. Access to safely managed sanitation services is defined as a 'private improved facility where faecal wastes are safely disposed on site or transported and treated off-site, including a handwashing facility with soap and water' (WHO 2017d). Again, the shortcomings in the indicators identified by our systematic literature review have been addressed

7 The data for this section were collected up till November 2017. 
Table 3 SDG 6 targets and indicators (resolution 313/2017)

Targets
6.1. By 2030, achieve universal and equitable
access to safe and affordable drinking water for all
6.2. By 2030, achieve access to adequate and
equitable sanitation and hygiene for all and end
open defecation, paying special attention to the
needs of women and girls and those in vulnerable
situations

6.3. By 2030 , improve water quality by reducing pollution, eliminating dumping and minimising release of hazardous chemicals and materials, halving the proportion of untreated wastewater and substantially increasing recycling and safe reuse globally

6.4. By 2030, substantially increase water-use efficiency across all sectors and ensure sustainable withdrawals and supply of freshwater to address water scarcity and substantially reduce the number of people suffering from water scarcity

6.5. By 2030, implement integrated water resources management at all levels, including through transboundary cooperation as appropriate

6.6. By 2020, protect and restore water-related ecosystems, including mountains, forests, wetlands, rivers, aquifers, and lakes

6.A. By 2030, expand international cooperation and capacity-building support to developing countries in water- and sanitation-related activities and programmes, including water harvesting, desalination, water efficiency, wastewater treatment, recycling, and reuse technologies

6.B. Support and strengthen the participation of local communities in improving water and sanitation management
Indicators

6.1.1. Proportion of population using safely managed drinking water services'

6.2.1. Proportion of population using safely managed sanitation services, including a hand-washing facility with soap and water

6.3.1. Proportion of wastewater safely treated

6.3.2. Proportion of bodies of water with good ambient water quality

6.4.1. Change in water-use efficiency over time 6.4.2. Level of water stress: freshwater withdrawal as a proportion of available freshwater resources

6.5.1. Degree of integrated water resources management implementation (0-100)

6.5.2. Proportion of transboundary basin area with an operational arrangement for water cooperation

6.6.1. Change in the extent of water-related ecosystems over time

6.A.1. Amount of water- and sanitation-related official development assistance that is part of a government-coordinated spending plan

6.B.1. Proportion of local administrative units with established and operational policies and procedures for participation of local communities in water and sanitation management

by SDG 6.2 indicator. Collection, transport and treatment of faecal waste and wastewater have been taken into account, as well as hygiene.

Despite this progress being made, we find that the SDG indicators for targets 6.1 and 6.2 lack transparency when it comes to the type of access people have to water and sanitation. We propose alternative indicators for targets 6.1 and 6.2, reflecting what type of access people have in urban and rural areas: a connection to centralised piped water supply and sanitation network or access to decentralised water and sanitation services (Table 4). The proposed indicators report on the degree to which governments have succeeded to expand centralised infrastructure to low- and middle income areas. We emphasised the need for government regulation, in response to the examples of water contamination and other public health and environmental risks related to pit latrines and septic tanks provided in the literature. It remains questionable whether pit latrines can be seen as adequate sanitation in urban areas. 
Criticisms regarding the need for integrated water resources management has been addressed by indicators 6.4, 6.5 and 6.6 (Table 3). A number of studies in the sample criticise the lack of consistent disaggregated data to be able to assess whether MDG 7c has reached disadvantaged groups. The principle of equality has been emphasised by SDG targets 6.1 and 6.2: 'equitable access' and 'paying special attention to the needs of women and girls and those in vulnerable situations'. JMP is planning to disaggregate data by sex, age and disability and by groups disadvantaged on the basis of ethnicity, race, religion, caste, migratory status or other characteristics. Access to water and sanitation will also be measured in schools and health centres.

Case studies in the sample show that, in the MDG period, governments have failed to invest effectively in infrastructure, expand piped infrastructure and protect the public against health risks and pollution of the environment. Yet, there are no consistent data to establish to what extent governments have failed or succeeded. Household surveys also have their limitations, with interviewers having little time to ask questions and possibly lacking the technical qualifications to judge whether sanitation infrastructure, for example, is safely constructed and emptied.

Future research could offer more insight into the sustainability of measures taken at national levels through systematic case studies. One of the objectives of in-depth studies is to monitor whether projected government and donor investments lead to actual expenditures in water and sanitation services in low- and middle-income areas, and if these services are sustainable. In-depth case studies also provide an opportunity to explore to what extent increased access to piped water supply and sewerage networks benefits disadvantaged groups, supplementing disaggregated data collected by JMP.

\section{Conclusion}

Academic criticism of MDG 7c mainly concerns shortcomings in the indicators for safe water and basic sanitation and the political dynamics behind the indicators. According to resolution 313/2017 and recent WHO reports (2017), the shortcomings in the indicators for safe water and basic sanitation have been addressed by SDG 6 . The indicator of 'safely managed water services' will take into account water quality, affordability, availability and accessibility. Collection, treatment and disposal of faecal sludge and wastewater have been included in the SDG indicator of 'safely managed sanitation service', while SDG 6 also includes targets and indicators on hygiene, wastewater treatment, and water scarcity, and emphasises equitable access. Data will be disaggregated by sex, age and disability and by groups disadvantaged on the basis of ethnicity, race, religion, caste, migratory status or other characteristics.

The SDG 6 indicators, however, lack transparency. The proposed indicators fail to report whether progress has been made through centralised piped infrastructure or decentralised options in cities. To gain more insight into the way progress has been made, we propose indicators that distinguish advancements made with regard to piped infrastructure and decentralised infrastructure. This is relevant because it will reveal the degree to which governments have succeeded in improving water services and sanitation through centralised infrastructure in low-and middle income areas. In addition, we propose adding regulation as a parameter to the SDG 6 indicators, especially for decentralised infrastructure such as pit latrines and septic tanks, which are crucial to preventing diseases and environmental contamination. 
Table 4 Proposed indicators for SDG 6 target 1 and 2

SDG 6.1 and 6.2 targets and indicators

Target 6.1 By 2030, achieve universal and equitable access to safe and affordable drinking water for all

SDG 6 indicator

Proposed indicators

6.1.1. Drinking water from an improved source which is located on the premises, available when needed and free of faecal and priority contamination

6.1.1. Proportion of the urban population in low, middle and high income areas with a connection to the centralised water supply network regulated by an independent public entity in terms of water quality, availability and price

6.1.2. Proportion of the urban population in low, middle and high income areas using alternative water supply sources regulated by an independent public entity in terms of water quality, availability and price

6.1.3. Proportion of the rural population using water supply sources regulated by an independent public entity in terms of water quality, availability and price. The water source is accessible within $30 \mathrm{~min}$ walking

Target 6.2. By 2030, achieve access to adequate and equitable sanitation and hygiene for all and end open defecation, paying special attention to the needs of women and girls and those in vulnerable situations

SDG 6 indicator

Proposed indicators
Private improved facility where faecal wastes are safely disposed on site or transported and treated off-site; plus a handwashing facility with soap and water

6.2.1. Proportion of the urban population in low, middle and high income areas with a connection to the centralised sewerage network regulated by an independent public entity. Wastewater is treated and safely disposed of

6.2.2. Proportion of the urban population in low, middle and high income areas using onsite sanitation options regulated by an independent public entity. Faecal waste is safely collected, transported and disposed of

6.2.3. Proportion of the rural population using onsite and offsite sanitation options regulated by an independent public entity. Faecal waste is safely collected, transported and disposed of

Hygiene is addressed through hygiene campaigns

We recommend that quantitative data on progress towards SDG 6 are complemented with in-depth case studies. Our research shows that the political challenges behind the indicators will not simply be solved by adding parameters to the indicators. In-depth case studies will improve our understanding of the level of investments made in water and sanitation in low-income areas, and whether such interventions are actually sustainable.

Open Access This article is distributed under the terms of the Creative Commons Attribution 4.0 International License (http://creativecommons.org/licenses/by/4.0/), which permits unrestricted use, distribution, and reproduction in any medium, provided you give appropriate credit to the original author(s) and the source, provide a link to the Creative Commons license, and indicate if changes were made. 


\section{References}

Adams, E. A., Boateng, G. O., \& Amoyaw, J. A. (2016). Socioeconomic and demographic predictors of potable water and sanitation access in Ghana. Social Indicators Research, 126(2), 673-687.

Adjei, P. O. W., \& Kyei, P. O. (2013). Linkages between income, housing quality and disease occurrence in rural Ghana. Journal of Housing and the Built Environment, 28(1), 35-49.

Aguilar, M. D., \& de Fuentes, A. G. (2007). Barriers to achieving the water and sanitation-related millennium development goals in Cancún, Mexico at the beginning of the twenty-first century. Environment and Urbanization, 19(1), 243-260.

Anand, P. B. (2007). Semantics of success or pragmatics of progress? An assessment of India's progress with drinking water supply. Journal of Environment and Development, 16(1), 32-57.

Ayalew, M., Chenoweth, J., Malcolm, R., Mulugetta, Y., Okotto, L. G., \& Pedley, S. (2014). Small independent water providers: Their position in the regulatory framework for the supply of water in Kenya and Ethiopia. Journal of Environmental Law, 26(1), 105-128.

Bain, R. E. S., Gundry, S. W., Wright, J. A., Yang, H., Pedley, S., \& Bartram, J. K. (2012). Accounting for water quality in monitoring access to safe drinking-water as part of the Millennium Development Goals: Lessons from five countries. Bulletin of the World Health Organization, 90(3), $228-235$.

Bartram, J., Brocklehurst, C., Brocklehurst, C., Luyendijk, R., Hossain, R., Wardlaw, T., et al. (2014). Global monitoring of water supply and sanitation: History, methods and future challenges. International Journal of Environmental Research and Public Health, 11(8), 8137-8165.

Baum, R., Luh, J., \& Bartram, J. (2013). Sanitation: A global estimate of sewerage connections without treatment and the resulting impact on MDG progress. Environmental Science and Technology, 47(4), 1994-2000.

Bennett, H. B., Shantz, A., Shin, G., Sampson, M. L., \& Meschke, J. S. (2010). Characterisation of the water quality from open and rope-pump shallow wells in rural Cambodia. Water Science and Technology, 61(2), 473-479.

Brown, J., Hien, Vo Thi, McMahan, L., Jenkins, M. W., Thie, L., Liang, K., et al. (2013). Relative benefits of on-plot water supply over other improved' sources in rural Vietnam. Tropical Medicine \& International Health, 18(1), 65-74.

Cho, D. I., Ogwang, T., \& Opio, C. (2010). Simplifying the water poverty index. Social Indicators Research, 97(2), 257-267.

Cotton, A., \& Bartram, J. (2008). Sanitation: On- or off-track? Issues of monitoring sanitation and the role of the joint monitoring programme. Waterlines, 27(1), 12-29.

De Gisi, S., Petta, L., \& Wendland, C. (2014). History and technology of Terra Preta sanitation. Sustainability (Switzerland), 6(3), 1328-1345.

Erni, M., Drechsel, P., Bader, H. P., Scheidegger, R., Zurbruegg, C., \& Kipfer, R. (2010). Bad for the environment, good for the farmer? Urban sanitation and nutrient flows. Irrigation and Drainage Systems, 24(1-2), 113-125.

Fisher, K. T. (2008). Politics and urban water supply. Development, 51(1), 30-36.

Flores Baquero, O., Jiménez Fdez. de Palencia, A., \& Pérez Foguet, A. (2016). Measuring disparities in access to water based on the normative content of the Human Right. Social Indicators Research, 127(2), 741-759.

Flörke, M., Kynast, E., Bärlund, I., Eisner, S., Wimmer, F., \& Alcamo, J. (2013). Domestic and industrial water uses of the past 60 years as a mirror of socio-economic development: A global simulation study. Global Environmental Change, 23(1), 144-156.

Gunawardana, I. P. P., \& Galagedara, L. W. (2013). A new approach to measure sanitation performance. Journal of Water Sanitation and Hygiene for Development, 3(2), 269-282.

Gutierrez, E. (2007). Delivering pro-poor water and sanitation services: The technical and political challenges in Malawi and Zambia. Geoforum, 38(5), 886-900.

Hadipuro, W. (2007). Water supply vulnerability assessment for sustainable livelihood. Journal of Environmental Assessment Policy and Management, 9(1), 121-135.

Hsieh, H., \& Shannon, S. E. (2005). Three approaches to qualitative content analysis. Qualitative Health Research, 15(9), 1277-1288.

Kite, G., Manuel Roche, J., \& Wise, L. (2014). Leaving no one behind under the post-2015 framework: Incentivizing equitable progress through data disaggregation and interim targets. Development (Basingstoke), 57(3-4), 376-387.

Koff, H., \& Maganda, C. (2016). The EU and the human right to water and sanitation: Normative coherence as the key to transformative development. European Journal of Development Research, 28(1), 91-110.

Laré-Dondarini, A. L. (2015). Analysis of household demand for improved sanitation: The case of green latrines in Dapaong city in northern Togo. Canadian Journal of Development Studies, 36(4), 555-572. 
Malik, O. A., Hsu, A., Johnson, L. A., \& de Sherbinin, A. (2015). A global indicator of wastewater treatment to inform the sustainable development goals (SDGs). Environmental Science \& Policy, 48, 172-185.

Moher, D., Liberati, A., Tetzlaff, J., Altman, D. G., Altman, D., Antes, G., et al. (2009). Preferred reporting items for systematic reviews and meta-analyses: The PRISMA statement. Annals of Internal Medicine, 151(4), 264-269.

Onda, K., LoBuglio, J., \& Bartram, J. (2012). Global access to safe water: Accounting for water quality and the resulting impact on MDG progress. International Journal of Environmental Research and Public Health, 9(3), 880-894.

O'Reilly, K. (2010). Combining sanitation and women's participation in water supply: An example from Rajasthan. Development in Practice, 20(1), 45-56.

Rajaraman, I., \& Gupta, M. (2016). Preserving the incentive properties of statutory grants. Economic and Political Weekly, 51(9), 79-84.

Rouse, M. (2014). The worldwide urban water and wastewater infrastructure challenge. International Journal of Water Resources Development, 30(1), 20-27.

Santos, M. E. (2013). Tracking poverty reduction in Bhutan: Income deprivation alongside deprivation in other sources of happiness. Social Indicators Research, 112(2), 259-290.

Satterthwaite, M. (2014). On rights-based partnerships to measure progress in water and sanitation. Science and Engineering Ethics, 20(4), 877-884.

Satterthwaite, D. (2016). Missing the millennium development goal targets for water and sanitation in urban areas. Environment and Urbanization, 28(1), 99-118.

Schaub-Jones, D. (2010). Should we view sanitation as just another business? The crucial role of sanitation entrepreneurship and the need for outside engagement. Enterprise Development and Microfinance, 21(3), 185-204.

Shelus, V., \& Hernandez, O. L. (2015). The usefulness of a hand washing proxy in large household surveys. Journal of Water Sanitation and Hygiene for Development, 5(4), 565-573.

Snehalatha, M., \& Anitha, V. (2012). India's total sanitation Campaign: Is it on the right track? Progress and issues of TSC in Andhra Pradesh. Journal of Rural Development, 31(2), 173-192.

Sorenson, S. B., Morssink, C., \& Campos, P. A. (2011). Safe access to safe water in low income countries: Water fetching in current times. Social Science and Medicine, 72(9), 1522-1526.

United Nations MDG Monitor. (2017). MDG 7: Ensure environmental sustainability. 6 June 2017, from http://www.mdgmonitor.org/mdg-7-ensure-environmental-sustainability/.

UNDP \& Institute for National Planning (INP). (2004). Egypt human development report 2004: Choosing decentralization for good governance.

United Nations. (2017). UN Millnenium Campaign. July 2017, from http://www.un.org/millenniumgoals/ bkgd.shtml.

Welle, K. (2014). Monitoring performance or performing monitoring? Exploring the power and political dynamics underlying monitoring the MDG for rural water in Ethiopia. Canadian Journal of Development Studies, 35(1), 155-169.

WHO. (2017a). Millenium development goals. 11 December 2017, from http://www.who.int/topics/mille nnium_development_goals/en/.

WHO. (2017b). Diseases and risks. 4 January 2017, from http://www.who.int/water_sanitation_health/disea ses-risks/en/.

WHO. (2017c). Annex 2: Safely managed sanitation services. November 2017, from http://www.who.int/ water_sanitation_health/monitoring/coverage/explanatorynote-sdg-621-safelymanagedsanitationsS ervices161027.pdf.

WHO. (2017d). Safely managed drinking water-Thematic report on drinking water. November 2017, from http://data.unicef.org/resources/safely-managed-drinking-water/.

WHO/UNICEF Joint Monitoring Programme. Improved and unimproved water and sanitation facilities. 7 June 2016, from http://www.wssinfo.org/definitions-methods/watsan-categories/.

Zawahri, N., Sowers, J., \& Weinthal, E. (2011). The politics of assessment: Water and sanitation MDGs in the Middle East. Development and Change, 42(5), 1153-1178. 